\title{
In Reference to "Nebulized Bronchodilators Instead of Metered-Dose Inhalers for Obstructive Pulmonary Symptoms"
}

\author{
Joshua LaBrin, MD, SFHM, FACP
}

Division of General Internal Medicine, Department of Medicine, University of Utah, Salt Lake City, Utah.

I read with great interest Moriates and Feldman's article advocating inhalers in obstructive disease. ${ }^{1}$ Although I agree with the main thoughts of their argument, there are issues for consideration.

Patient education on proper inhaler use is needed, and Press et $\mathrm{al}^{2}{ }^{2}$ offer hope of improvement. However, as acknowledged by Press et al., with any skill, it is unclear whether mastery is retained long term. Molimard et al. ${ }^{3}$ found inhaler misuse occurring in the outpatient setting, suggesting this may be an ongoing problem, or that some patients may be unable to master this complex skill.

Inhaler therapy is recommended due to the benefits mentioned by the authors. However, discharge planning should focus more on appropriate device selection. Mahler et al. ${ }^{4}$ identified patients with chronic obstructive pulmonary disease with a suboptimal peak inspiratory flow rate in whom use of an inhaler might be ineffective. A subsequent study in this population demonstrated significant improvements in forced expiratory volume in $1 \mathrm{sec}-$ ond, total lung capacity, and inspiratory capacity with nebulizer therapy compared to a dry powder inhaler. ${ }^{5}$ Other high-risk populations may include patients with neuromuscular disease or impaired manual dexterity (eg, Parkinson's, poststroke) inhibiting proper inhaler use.

Therefore, although metered-dose inhaler therapy is preferred over nebulized therapy, I would caution too sweeping a recommendation missing certain populations with "a reason" for alternative delivery.

\section{References}

1. Moriates C, Feldman L. Nebulized bronchodilators instead of metered-dose inhalers for obstructive pulmonary symptoms. J Hosp Med. 2015;10(10):691-693.

2. Press VG, Arora VM, Shah LM, et al. Misuse of respiratory inhalers in hospitalized patients with asthma or COPD. J Gen Intern Med. 2011;26(6):635-642.

3. Molimard M, Raherison C, Lignot S, Depont F, Abouelfath A, Moore N. Assessment of handling of inhaler devices in real life: an observational study in 3811 patients in primary care. J Aerosol Med. 2003;16(3):249-254.

4. Mahler DA, Waterman LA, Gifford AH. Prevalence and COPD phenotype for a suboptimal peak inspiratory flow rate against the simulated resistance of the Diskus dry powder inhaler. J Aerosol Med Pulm Drug Deliv. 2013;26(3):174-179.

5. Mahler DA, Waterman LA, Ward J, Gifford AH. Comparison of dry powder versus nebulized beta-agonist in patients with COPD who have suboptimal peak inspiratory flow rate. J Aerosol Med Pulm Drug Deliv. 2014;27(2):103-109.

Received: November 9 , 2015: Accepted: November 20, 2015 2016 Society of Hospital Medicine DOI 10.1002/jhm.2532

Published online in Wiley Online Library (Wileyonlinelibrary.com).

\section{The Authors Reply "Nebulized Bronchodilators Instead of Metered-Dose Inhalers for Obstructive Pulmonary Symptoms"}

\author{
Christopher Moriates, MD¹, Leonard Feldman, MD²
}

${ }^{1}$ Division of Hospital Medicine, University of California at San Francisco, San Francisco, California; ${ }^{2}$ Department of Medicine, Johns Hopkins University School of Medicine, Baltimore, Maryland.

We certainly agree with Dr. LaBrin that there are a minority of inpatients and outpatients who might benefit from nebulizer therapy. In our review article, ${ }^{1}$ we attempted not to make a sweeping generalization, even if we did not explicitly mention some chronic obstructive pulmonary disease patients with suboptimal peak inspiratory flow rate (PIFR) or those with neuromuscular disease as populations where nebulizer therapy may be preferred. Our recommendation included this statement: "Inpatient use of nebulizers may be more appropriate than metered-dose inhalers (MDIs) for patients with dementia or altered mental status, as well as those in extreme distress resulting in an inability to coordinate inhaler usage. Very low health literacy may be an additional barrier to appropriate MDI teaching and usage." ${ }^{1}$ Our list was not all-inclusive, and patients with suboptimal PIFR or with neuromuscular disease are good additions to this recommendation.
As for proper MDI technique, it is unclear whether MDI teaching will result in long-term mastery of the skill. ${ }^{2}$ The only way to master a skill is to practice it. Thus, by prescribing MDIs and training patients on their proper usage during every admission, we will provide medically appropriate patients with many opportunities to practice the skill and reinforce effective techniques.

\section{References}

1. Moriates C, Feldman L. Nebulized bronchodilators instead of metered-dose inhalers for obstructive pulmonary symptoms. J Hosp Med. 2015;10(10):691-693.

2. Press VG, Arora VM, Shah LM, et al. Misuse of respiratory inhalers in hospitalized patients with asthma or COPD. J Gen Intern Med. 2011;26(6):635-642.

Received: November 9, 2015; Accepted: November 20, 2015 2016 Society of Hospital Medicine DOI 10.1002/jhm.2531 Published online in Wiley Online Library (Wileyonlinelibrary.com). 